\title{
EDITORIAL
}

\section{Theory in learning technology}

This special issue is being published at a significant point in time in relation to simultaneous changes in higher education, in technology and in the field of learning technology itself. As the 2011 ALT C conference themes clearly state, learning technology needs to learn to thrive in a colder and more challenging climate. In this difficult political and economic environment technological trends continue to develop in terms of mobility, cloud computing, ubiquity and the emergence of what has been called big data. E-learning has become mainstream and the field of learning technology itself is beginning to stabilisE as a profession. Profession here is understood as a knowledge-based occupation and a form of cultural work where the tasks addressed are human problems amenable to expert advice and distinguishable from other kinds of work by the fact that it is underpinned by abstract knowledge (Macdonald, 1995).

Abstract knowledge is the focus of this special issue, in the form of theory. The hallmarks of a profession include both a codified body of practices (embodied knowledge including competence) and abstract knowledge in the form of theory which is expressed in a codified body of principles; in conceptual knowledge (Denning 2001 ${ }^{1}$ ). Indeed learning technology, like other applied technology fields, has a distinct relationship to explicit, codified, systematic and scientific knowledge (Jones 2004). Czerniewicz (2010) has shown how learning technology as an applied field takes the form of a horizontal knowledge structure, segmented and expressed as co-existent parallel specialist 'languages', with a tendency to repeat and proliferate. A Bernsteinian framework shows how theory is manifest in a "general approach discursive plane", where metalanguages are produced to legitimize how phenomena are understood and interpreted, and to determine what counts as a proper description. It is important that the theories expressed through these metalanguages are developed and made explicit. Coherent theoretical frameworks are needed to enable integration across the segmented clusters so that generalizations can be made, lessons learnt across multiple sites, and a community of researchers enabled to share a common language to build knowledge together.

In addition, because of the emergent nature of the field and the particular nature of learning technology in terms of practice, several related issues pertaining to theory and its role arise. These include:

- the place of theory in an applied practice-based field;

- the legitimacy of specific theories;

- the related contestation between theoretical positions and claims; and

- the tensions and disjunctures between the empirical and the theoretical in research. 
The need for theory development in learning technology echoes arguments made in educational research more broadly, where for example Ashwin (2009) has argued that research in higher education has been about exemplification rather than about theory development. The case for theory and for theory development is unsurprisingly one that weaves through all the papers in this special issue. In an extended and articulate case, Bennett and Oliver (this issue) argue that the lack of theoretical perspective in learning technology risks making the field at best one that is "narrow and derivative", and that the focus on applied design work in learning technology is too easily driven by common sense assumptions associated with matters of practical implementation. Both Bennett and Oliver and Howard and Maton (this issue) make the case for the need to build theory and Howard and Maton argue that without theory the danger will be that knowledge remains at the level of empirical description, rather than resting on the principles underlying the data. We believe that the papers in this Special Issue provide an antidote to these concerns, providing numerous examples of the opportunities for exploring the role of theory in learning technology research.

In the first instance, authors in this special collection theorise the applied nature of the field itself by conceptualising different aspects of use and of practice. Cram et al. (this issue) consider the practices of problem solving as understood by theories of expertise while Johri (this issue), drawing on Orlikowski, makes the case for practicebased bricolage. Such practice-based theorisations are welcome additions to learning technology, because they demonstrate in different ways how knowingin-action and reflective practice are intimately associated with theoretical knowledge. The field's traditional focus on design is not neglected, and we value Paavola et al. (this issue) for rigorously problematising the challenges associated with theorising design principles. It is worth repeating their conclusions that "conceptualisations can be more resistant to change than expected" and that "both practical applications and theoretical development require conscious development and cannot be taken for granted as a result of design-based research". This kind of honesty is essential for meaningful progress to be made in theory development in the field.

Also essential is a reminder of the inextricable relationship between the empirical and the conceptual, especially relevant in the current climate of big data and learning analytics. We find Sayer's (1992) three versions of theory helpful as a starting point, as he considers the three dimensions of theory as follows:

(1) Theory as an ordering framework which permits observational data to be used for predicting and explaining empirical events

(2) Theory as conceptualisation, prescribes a particular way of conceptualising something

(3) Theory as hypothesis or explanation (Sayer 1992, 50)

Sayer criticises the ordering framework (1) and hypothesis and explanatory views of theory (3) for their failure to deal with the indirect nature of our knowledge of the world. In his view conceptualisation lies at the heart of observation, a point of contact made famous in Einstein's comment that it is theory that decides what we observe ${ }^{2}$. Data is not neutral, its very selection indicates a theoretical perspective. Data does not produce facts that are direct reflections of the world, rather facts about the world, like theory, are constructs of human cultural engagement with the world and are never direct. In our view theory can generalise across a variety of 
contexts and across time and at its best can compress experience into robust, considered and usable forms.

Because we do not believe that facts provide direct access to the world we stand against the tradition (perhaps especially strong in England) to distrust theory and to emphasise the empirical. We stand firmly against this trend and argue that a sound theoretical basis for learning technology in conceptualising the research object is essential and that empirical work that fails to engage with theory has a very limited ability to develop and inform the field. Currently the anti-theoretical stance has taken on a new importance with the development of the idea of a "fourth paradigm" (Hey, Tansley, and Tolle 2009). Famously Anderson has claimed:

This is a world where massive amounts of data and applied mathematics replace every other tool that might be brought to bear. Out with every theory of human behavior, from linguistics to sociology. Forget taxonomy, ontology, and psychology. Who knows why people do what they do? The point is they do it, and we can track and measure it with unprecedented fidelity. With enough data, the numbers speak for themselves. (Anderson 2008)

In a world of big data the idea that theory is at best irrelevant and at worst counterproductive is extremely dangerous. In educational technology the idea of learner analytics could easily be developed to suggest that if we simply collect enough raw data on students then theory will become irrelevant. Such a stance in relation to theory ignores all the known weakness of numerical data and the weaknesses of 'big data' in particular (see for example boyd and Crawford 2011). In a world in which there is a data flood in which new data sources impact on all the disciplines that learning technology draws on, a renewed engagement with theory will be essential to ensure that the data we collect for analysis is not garbage so that the answers derived from it are not just as poor.

It is notable that the papers in this issue are largely drawn from the social sciences, even when these are situated in relation to technology and information sciences. This suggests either a narrowing or a resolution and the beginning of some coherence with regard to the multi-disciplinary nature of the field. Learning technology has of necessity drawn on a range of disciplinary areas that often have contrasting and even conflicting assumptions about the nature of knowledge and how theoretical understanding can be achieved. Apart from education and educational theory, learning technology has drawn significantly from a range of disciplines including psychology, sociology and anthropology, computer and information sciences etc. A consequence of this diversity is that the claims to knowledge are often based on deeply ingrained philosophical stances, disciplinary paradigms and entrenched research methodologies. A striking example of this range is the positivist influenced paradigm of research commonly found in psychology, involving largely quantitative methods and experimentation, contrasted with the research paradigm in the cultural and social sciences which adopts a largely interpretivist approach and conducts research in real-life settings. The sheer range of disciplinary sources presents difficulties for anyone trying to outline or develop a coherent theoretical stance applying to learning technology as a whole.

It is interesting that the call for papers for this special issue on theory in learning technology drew few papers with an emphasis on learning theory and that there is little evidence of a strong psychological, computer science or educational research influence. It is also of note that the dominance of learning 
theory especially in terms of the instructivist/constructivist see-saw noted in recent years (see Czerniewicz 2010) is barely evident here. There is a sociological bent indicative of what we perceive as a general shift to the socio-cultural context of learning. We note too an emphasis on and an interest in the persistent problem for learning technology: the relationship between technology and learning and the co-construction of education and technology. Three of the papers in this edition draw on Actor Network Theory (ANT) (Johri, Edwards et al., and Wright and Parchoma this issue) while a third makes use of Social Studies of Science and Technology (SCOT) (Jones and Bissell this issue). These papers contribute to exploring the relationship between new technologies and learning. All three suggest an interpretive flexibility in relation to technology that is not fixed by design and emerges in interaction and use.

The articles in this issue also demonstrate how theory can locate discussion and research in a broader academic and scholarly discourse (see for example Johri in this issue and his consideration of four dimensions of theory). Equally theory can be criticised for occluding aspects of experience, making researchers and practitioners blind to some aspects of their own context, or the context of their work, and making the simple appear both complex and obscure. Two papers in this special issue interrogate dominant discourses (Edwards, Tracy, and Jordan; Wright and Parchoma). Wright and Parchoma question the discourse surrounding the use of mobile devices in education while Edwards, Tracy, and Jordan suggest that framing education as spatial orderings raises questions for those dominant discourses that focus on learning and teaching in education. The article by Hall (this issue) makes a general call for placing critique, based on a deep understanding of the socio-cultural contexts within which technology is deployed, at the core of learning technology research. The current major crisis in neo-liberal capitalism suggests that critique is likely to emerge as a major theme in the near future. As governments cut public expenditure and look for quick fixes to fundamental problems, learning technology may become a battleground in which economic constraints and a consumerist philosophy applied to education come into conflict with popular movements focused on the public role of the university.

In this harsh environment original responses are essential. The collection of articles published in this special issue provides a rich diversity of sites and an array of conceptual approaches to learning technology research and innovation. The cases provided are evidence of proactive engagements with challenging conditions through robust research which is slowly closing the spaces between fragmented thinking and isolationist approaches. This is a contribution to both community building and cumulative knowledge building in the field.

\section{Notes}

1. See an elaboration of this in Hodgkinson-Williams and Czerniewicz, (2007).

2. This quote was related by Heisenberg and quoted in Unification of Fundamental Forces (1990) by Abdus Salam according to http://en.wikiquote.org/wiki/Albert_Einstein.

\section{References}

Anderson, C. 2008. The end of theory: The data deluge makes the scientific method obsolete. Wired Magazine 16, no. 7 [Online]. http://www.wired.com/science/discoveries/ magazine/16-07/pb_theory (accessed September 27, 2011). 
Ashwin, P. 2009. Relations between theory and data in research in higher education. Education Research Seminar, October 7, Lancaster University. http://www.lancs.ac.uk/fass/ doc_library/edres/09seminars/ashwin_07.10.09.pdf (accessed September 27, 2011).

boyd, D., and K. Crawford. 2011. Six provocations for big data. Paper presented at Oxford Internet Institute's "A decade in Internet time: Symposium on the dynamics of the Internet and society", September 21. SSRN. http://ssrn.com/abstract=1926431 (accessed September 27, 2011).

Czerniewicz, L. 2010. Educational technology - Mapping the terrain with Bernstein as cartographer. Journal of Computer Assisted Learning (JCAL) 26, no. 6: 523-34.

Denning, P.J. 2001. The profession of IT: Who are we? Communications of the ACM 44, no. 2: $15-9$.

Hey, T., S. Tansley, and K. Tolle, eds. 2009.The fourth paradigm data-intensive scientific discovery. Microsoft Research, Redmond, WA. http://research.microsoft.com/en-us/collaboration/fourthparadigm/ (accessed September 27, 2011).

Hodgkinson-Williams, H., and L. Czerniewicz. 2007. Educational technologists in higher education institutions in South Africa: Moving beyond random acts of progress. Paper presented at Research Based Elearning, Hogsback. http://www.cet.uct.ac.za/files/Hodgkinson-Williams $\% 20 \& \% 20$ Czerniewicz $\% 20$ Full $\% 20$ paper.pdf.

Jones, C. 2004. Theory and the practices of learning technology. In Networked learning 2004: Proceedings of the fourth international conference on networked learning 2004, ed. S. Banks, P. Goodyear, V. Hodgson, C. Jones, V. Lally, D. McConnell, and C. Steeples. Lancaster: Lancaster University.

Macdonald, K. 1995. The sociology of the professions. London: SAGE Publications.

Sayer, A. 1992. Method in social science: A realist approach. 2nd ed. London: Routledge.

Chris Jones

The Open University, UK

c.r.jones@open.ac.uk

Laura Czerniewicz

University of Cape Town, South Africa

Laura.Czerniewicz@uct.ac.za 